\title{
Data Compression Error
}

National Cancer Institute

\section{Source}

National Cancer Institute. Data Compression Error. NCI Thesaurus. Code C92039.

Data was lost or corrupted during the operation of reducing storage space or communication bandwidth. 